Check for updates

Cite this: RSC Adv., 2017, 7, 43845

Accepted 28th August 2017

DOI: $10.1039 / c 7 r a 08248 g$

rsc.li/rsc-advances

\section{Cyanobenzene-containing tetraphenylethene derivatives with aggregation-induced emission and self-recovering mechanofluorochromic characteristics $\dagger$}

\author{
Fei Zhao, Congbin Fan, (D) Zhao Chen, (D) * Gang Liu and Shouzhi Pu*
}

We report two constitutional isomers based on tetraphenylethene and cyanobenzene units via typical Suzuki coupling reaction. These target luminogens show obvious aggregation-induced emission (AIE) and self-reversible mechanofluorochromic characteristics.
Over the past decades, the exploitation of smart luminescent materials sensitive to environmental stimuli has attracted a great deal of attention due to their potential uses in some areas such as in fluorescent switches and sensors. ${ }^{1}$ Mechanical force is one of the most common external stimuli, and thus mechanofluorochromic materials, which show fluorescent changes resulting from mechanical force stimuli, can be applied as mechanical force-sensing systems.

High intensity solid-state emission and a prominent color contrast before and after the application of mechanical stimulus are very significant for the effective application of mechanochromic luminescence materials. ${ }^{2}$ However, many fluorescent materials are highly luminescent in their dilute solutions but become weakly emissive when aggregated into the condensed phase because of the existence of notorious aggregation caused quenching (ACQ) phenomenon, ${ }^{3}$ which largely limits the effective development of mechanofluorochromic materials. Fortunately, in 2001, Tang et al. reported several propeller-shaped compounds exhibiting intriguing aggregation-induced emission (AIE) phenomenon, which is different from the ACQ phenomenon. ${ }^{4}$ Luminescent molecules with AIE property are highly emissive in the aggregation state. Obviously, the discovery of mechanochromic compounds with AIE behavior has contributed to the high-efficiency application of mechanochromic fluorescent materials. ${ }^{5}$ It is well-known that tetraphenylethene (TPE) is a typical AIE unit, and lots of TPE-based derivatives have been shown to be AIE-active. ${ }^{6}$ Therefore, it is

Jiangxi Key Laboratory of Organic Chemistry, Jiangxi Science and Technology Normal University, Nanchang 330013, PR China. E-mail: chenzhao666@126.com; pushouzhi@tsinghua.org.cn

$\uparrow$ Electronic supplementary information (ESI) available: UV-Vis absorption spectra of luminogens 1 and 2 in $D M F-\mathrm{H}_{2} \mathrm{O}$ mixtures with different water contents, and characterization datas mentioned in the paper. CCDC 1553506 and 1553507. For ESI and crystallographic data in CIF or other electronic format see DOI: $10.1039 / \mathrm{c} 7 \mathrm{ra} 08248 \mathrm{~g}$ a significative research topic to design and synthesize mechanofluorochromic luminogens with TPE unit.

To date, a majority of mechanochromic luminogens usually require solvents fumigation or heat to achieve the recovery of mechanochromic luminescence. ${ }^{7}$ In contrast, it is quite rare to mechanochromism materials with spontaneous recovery at room temperature after mechanical grinding. ${ }^{8}$ It is challenging to recover autonomously of mechanochromic luminescence without using any external stimuli, and the corresponding mechanochromism materials are also rather important and valuable. For instance, smart materials with self-reversible mechanofluorochromic behavior can be applied to construct dynamic random access memory (DRAM) ${ }^{8 g}$ In this article, two novel luminogens (Chart 1) based on tetraphenylethene and cyanobenzene units were successfully designed and synthesized. The corresponding synthetic routes and characterization of compounds 1 and 2 are provided in the ESI. $\uparrow$ AIE and mechanofluorochromic characteristics of these constitutional isomers were systematically investigated, and the results indicated that the two compounds exhibited obvious AIE and

(a)
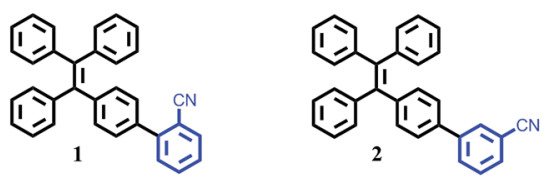

(b)

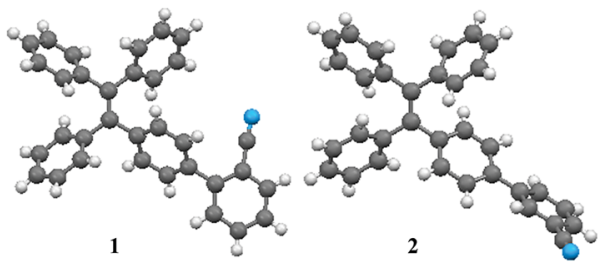

Chart 1 (a) The molecular structures of compounds 1 and 2. (b) The configuration of a compound 1 or 2 molecule taken form the single crystal structure. 
mechanofluorochromic characteristics. More importantly, their mechanofluorochromic behaviors were self-reversible within 10 minutes.

We initially investigated the AIE behaviors of compounds 1 and 2, the ultraviolet (UV)-visible absorption spectra and the photoluminescence (PL) spectra of luminogens 1 and 2 were systematically studied. The results indicated that the absorption spectra exhibited level-off tails in the visible-light region as the water fraction $\left(f_{\mathrm{w}}\right)$ values were increased (Fig. S1 and S2, ESI $\dagger$ ). It is well-known that such spectral tails can be attributed to the Mie scattering effect, which is commonly associated with the generation of nano-aggregates. ${ }^{9}$ As shown in Fig. 1, luminogen 1 showed extremely weak PL intensity. Interestingly, when the $f_{\mathrm{w}}$ in the DMF solution was increased to $70 \%$, an obvious emission band could be observed with a $\lambda_{\max }$ at $485 \mathrm{~nm}$, and a blue-green fluorescence was formed. As the water content was further increased to $90 \%$, the intensity of emission peak at $485 \mathrm{~nm}$ was approximately 2392-fold higher than that in pure DMF, and a bright blue-green luminescence could be observed.

Clearly, water is a poor solvent of luminogen 1 . Therefore, the generation of the blue-green emission can be attributed to the aggregate formation. ${ }^{\mathbf{1 0}}$ Indeed, the nano-aggregates obtained were verified via scanning electron microscope (SEM). As can be seen in Fig. 2, the SEM image showed that compound 1 tended to aggregate in DMF-water mixture with $f_{\mathrm{w}}=90 \%$. Thus, $\mathbf{1}$ is AIE-active, and its AIE property is triggered by the restricted intramolecular rotation. ${ }^{11}$ As shown in Fig. S3, $\dagger$ luminogen 2 also exhibited obvious AIE behavior, and the related SEM images are provided in Fig. S4 (ESI $\dagger$ ).

Subsequently, the mechanochromic luminescence properties of compounds $\mathbf{1}$ and $\mathbf{2}$ were further explored by solid-state PL spectroscopy. As presented in Fig. 3, the as-synthesized sample of 1 showed strong blue fluorescence with an luminescence quantum yield up to $74.6 \%$ at $466 \mathrm{~nm}$. However, a new
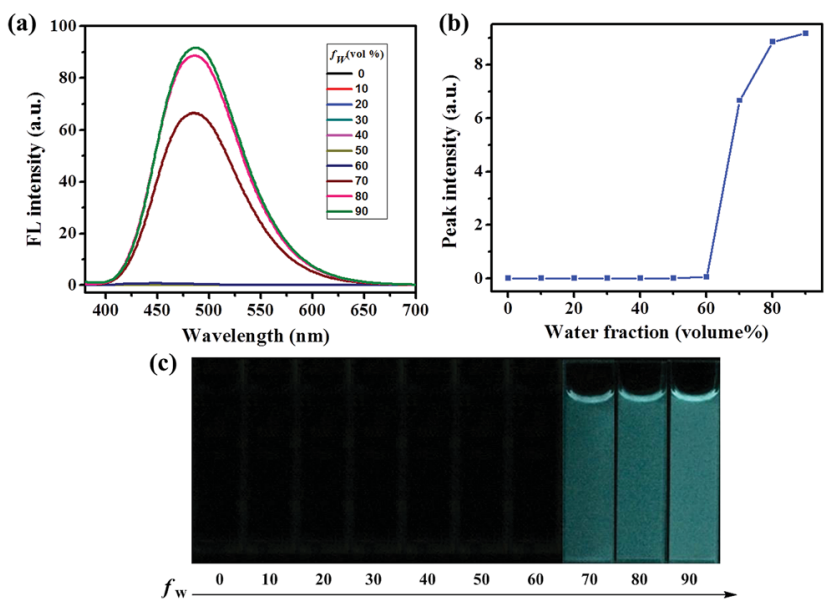

Fig. 1 (a) PL spectra of the dilute solutions of compound $1(2.0 \times$ $10^{-5} \mathrm{~mol} \mathrm{~L}^{-1}$ ) in DMF-water mixtures with different water content $(0-90 \%)$. Excitation wavelength $=365 \mathrm{~nm}$. (b) Changes in the emission intensity of compound 1 at $485 \mathrm{~nm}$ in DMF-water mixtures with various volume fractions of water $(0-90 \%)$. (c) $\mathrm{PL}$ images of compound $1\left(2.0 \times 10^{-5} \mathrm{~mol} \mathrm{~L}^{-1}\right)$ in various DMF-water mixtures with diverse $f_{\mathrm{w}}$ values $(0-90 \%)$ under $365 \mathrm{~nm}$ UV light.

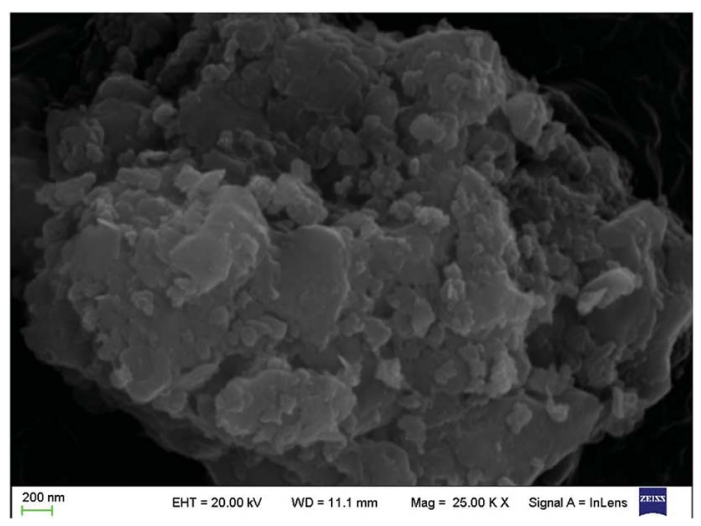

Fig. 2 SEM image of compound $1\left(2.0 \times 10^{-5} \mathrm{~mol} \mathrm{~L}^{-1}\right)$ formed from DMF/water mixture $\left(f_{\mathrm{w}}=90 \%\right)$.

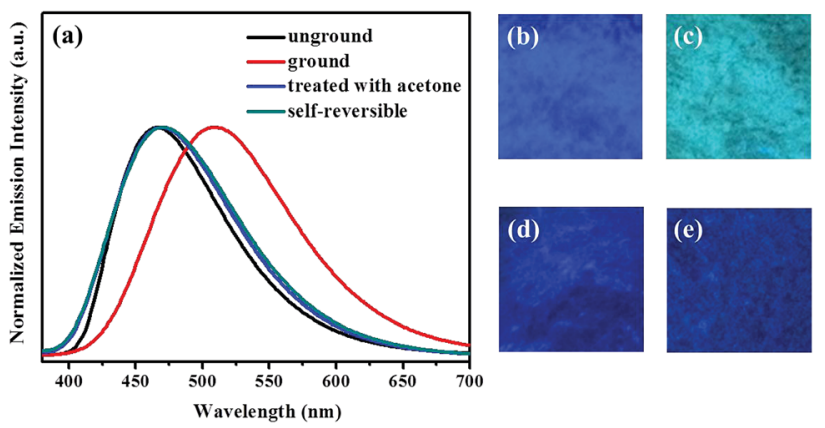

Fig. 3 (a) PL spectra of compound 1 at different conditions. Excitation wavelength: $365 \mathrm{~nm}$. Photographic images of compound 1 under irradiation with UV light at $365 \mathrm{~nm}$ : (b) the as-synthesized solid sample. (c) The entirely ground sample. (d) Self-reversible sample (within 10 minutes). (e) The sample after treatment with acetone vapor.

emission band centered at $509 \mathrm{~nm}$ was visible upon gentle grinding of 1 via a pestle or a spatula. Meanwhile, the blue lightemitting solid was converted into blue-green luminescent powder, and its absolute luminescence quantum yield was as high as $91.2 \%$. Furthermore, the initial blue fluorescence could be completely restored after fuming with acetone solvent vapor for $1 \mathrm{~min}$. More importantly, the blue-green luminescence of the ground sample could be robustly self-recovered back to the original blue light-emitting condition within 10 minutes. The self-recovering nature is very valuable for realizing volatile optical memory.

In addition, this self-reversible mechanofluorochromic phenomenon could be repeated many times between blue and blue-green emission colors (Fig. 4). As showed in Fig. 5, the mechanochromic blue-green fluorescence of compound 2 could also be restored to the initial color spontaneously without applying any other stimuli. Moreover, this self-reversible transition was also realized within 10 minutes, suggesting luminogen 2 also possessed excellent self-reversible mechanochromism behavior. This reversible mechanofluorochromic conversion of 2 could be repeated numerous times as well (Fig. 6).

It was speculated that external mechanical stimulation possibly resulted in a change in the molecular morphology. To 


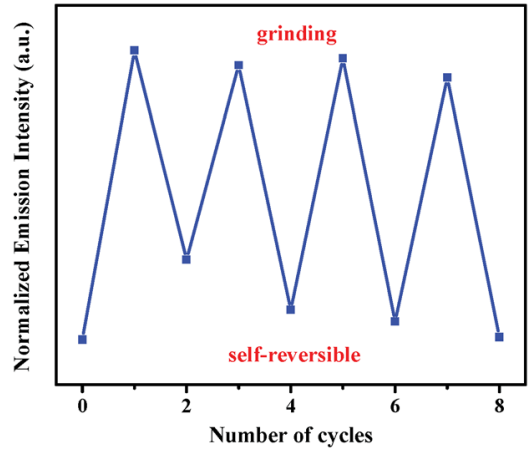

Fig. 4 Self-reversible mechanofluorochromic processes of compound 1 at $509 \mathrm{~nm}$.
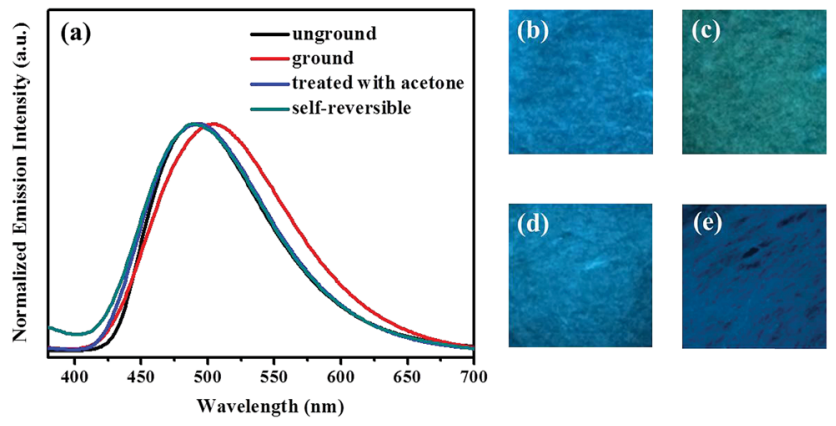

Fig. 5 (a) PL spectra of compound 2 at different conditions. Excitation wavelength: $365 \mathrm{~nm}$. Photographic images of compound 2 under irradiation with UV light at $365 \mathrm{~nm}$ : (b) the as-synthesized solid sample. (c) The entirely ground sample. (d) Self-reversible sample (within 10 minutes). (e) The sample after treatment with acetone vapor.

gain further insight into this possible mechanism for mechanochromic phenomenon of $\mathbf{1}$ or 2 , powder X-ray diffraction (XRD) analyses for structural transformations of $\mathbf{1}$ and $\mathbf{2}$ were performed. As can be seen in Fig. 7, the XRD patterns of the asprepared solid samples 1 and $\mathbf{2}$ exhibited a number of sharp and intense diffraction peaks, which were consistent with their crystalline nature. In contrast, these intense XRD reflection peaks could no longer be observed upon exposure to external pressure, indicative of their amorphous nature. Following solvent treatment or placed at room temperature within

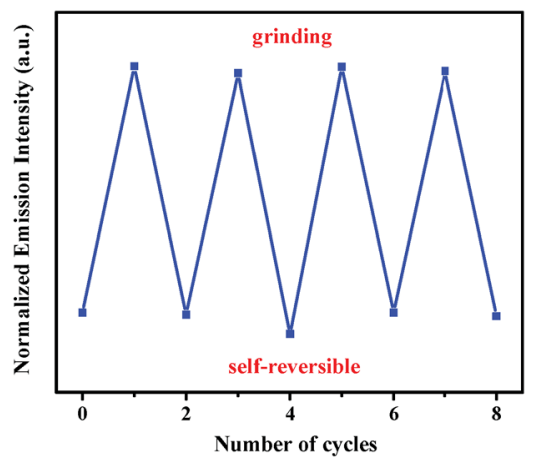

Fig. 6 Self-reversible compound 2 at $505 \mathrm{~nm}$.
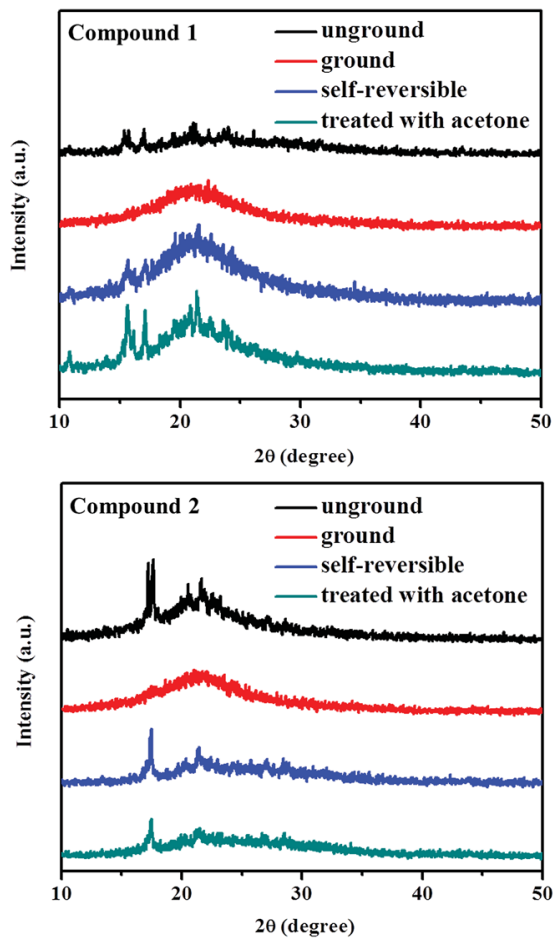

Fig. 7 PXRD patterns of compounds 1 and 2 in different solid states: the unground solid samples, the ground solid samples, self-reversible solid samples and the solid samples after treatment with acetone vapor.

10 minutes of the ground samples, the initial diffraction peaks were attained again, which indicated the conversion of an amorphous to crystalline phase. As a consequence, the powder XRD research results confirmed that the self-recovering mechanofluorochromic characteristics of luminogens 1 and 2 were related to the reversible morphological transition between an ordered crystalline state and a disordered amorphous state. The amorphous state of $\mathbf{1}$ or $\mathbf{2}$ could be converted to the crystalline state even at room temperature. As a result, the mechanochromic luminescence of $\mathbf{1}$ or $\mathbf{2}$ could be spontaneously restored to the initial color.

Fortunately, single crystals of compound $\mathbf{1}$ and compound $\mathbf{2}$ appropriate for X-ray structure analysis were obtained by means of recrystallization from dichloromethane/ $n$-hexane. Detailed crystal data are summarized in Tables S1 and S2 (ESI $\dagger$ ). As can be seen from the Fig. 8, the molecular conformation of 1 is twisted, and the presence of weak $\mathrm{C}-\mathrm{H} \cdots \pi$ interactions $\left(d_{\mathrm{C}-\mathrm{H} \cdots \pi}=2.745 \AA, 2.746 \AA\right)$ contributes to the molecular packing of 1. Meanwhile, the lack of a strong intermolecular force and the twisted molecular conformation of $\mathbf{1}$ lead to a loose packing motif. The structural organization of compound 2 was similar to 1 (Fig. $\mathrm{S} 5, \dagger d_{\mathrm{C}-\mathrm{H} \cdots \mathrm{N}}=2.606 \AA$, $2.865 \AA$.. $d_{\mathrm{C}-\mathrm{H} \cdots \pi}=$ $2.447 \AA$, ESI $\dagger$ ). Therefore, when the solid sample of compound 1 or $\mathbf{2}$ is ground, the ordered crystal packing of $\mathbf{1}$ or $\mathbf{2}$ may readily collapse, and a metastable state is formed. As a result, the solidstate PL colors of $\mathbf{1}$ and $\mathbf{2}$ were changed to blue-green.

In conclusion, two mechanofluorochromic constitutional isomers based on tetraphenylethene and cyanobenzene units 


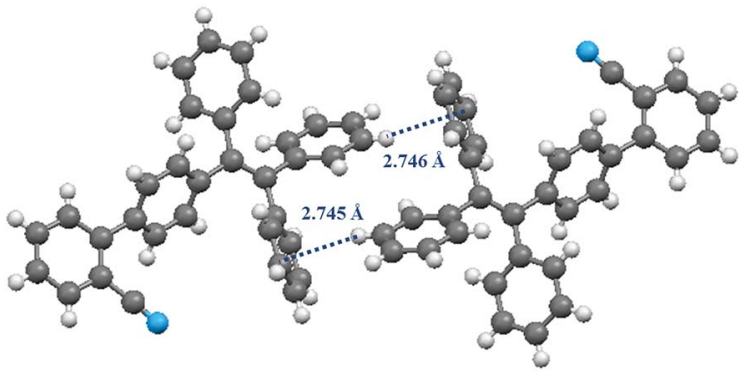

Fig. 8 The structural organization of compound 1.

were designed and synthesized. Investigation of aggregationinduced properties showed that compounds $\mathbf{1}$ and 2 possessed obvious AIE characteristics. In addition, mechanofluorochromic studies have confirmed that luminogens $\mathbf{1}$ and $\mathbf{2}$ exhibited reversible mechanochromic luminescence behavior involving the changes between blue and blue-green emissions. Furthermore, the mechanochromic blue-green luminescence of $\mathbf{1}$ or $\mathbf{2}$ could be spontaneously restored to the initial blue color within 10 minutes. The results of this work will be beneficial to the rational design of self-reversible mechanochromic fluorescence materials with AIE behavior. Further studies on the design of new highly emissive self-recovering mechanofluorochromic materials are in progress.

\section{Conflicts of interest}

There are no conflicts to declare.

\section{Acknowledgements}

The authors are grateful for the financial support from the National Natural Science Foundation of China (21702079 and 21662015), the Project of Jiangxi Sci-Tech Innovative Team (20142BCB24012), the Project of Jiangxi Academic and Technological leader (20142BCB22010), the key project of Natural Science Foundation of Jiangxi Province (20171ACB20025), the youth project of Natural Science Foundation of Jiangxi Province (20171BAB213004), and the Project of the Science Fund of Jiangxi Education Office (GJJ160764).

\section{Notes and references}

1 (a) B. Xu, Z. Chi, X. Zhang, H. Li, C. Chen, S. Liu, Y. Zhang and J. Xu, Chem. Commun., 2011, 47, 11080-11082; (b) Z. Chen, D. Wu, X. Han, Y. Nie, J. Yin, G.-A. Yu and S. H. Liu, RSC Adv., 2014, 4, 63985-63988; (c) Z. Ma, F. Yang, Z. Wang and X. Jia, Tetrahedron Lett., 2015, 56, 393-396; (d) Y. Cai, Z. Guo, J. Chen, W. Li, L. Zhong, Y. Gao, L. Jiang, L. Chi, H. Tian and W.-H. Zhu, J. Am. Chem. Soc., 2016, 138, 2219-2224; (e) Z. Chen, G. Liu, S. Pu and S. H. Liu, Dyes Pigm., 2017, 143, 409-415; (f) J. Zhang, Z. Chen, X.-Y. Wang, S.-Z. Guo, Y.-B. Dong, G.-A. Yu, J. Yin and S.-H. Liu, Sens. Actuators, B, 2017, 246, 570-577.

2 (a) J. Luo, L.-Y. Li, Y. Song and J. Pei, Chem.-Eur. J., 2011, 17, 10515-10519; (b) H.-J. Kim, D. R. Whang, J. Gierschner, C. H. Lee and S. Y. Park, Angew. Chem., Int. Ed., 2015, 54, 1-5; (c) Y. Q. Dong, J. W. Y. Lam and B. Z. Tang, J. Phys. Chem. Lett., 2015, 6, 3429-3436; (d) Z. Chen, Y. Nie and S. H. Liu, RSC Adv., 2016, 6, 73933-73938; (e) Z. Chen, J. Zhang, M. Song, J. Yin, G.-A. Yu and S. H. Liu, Chem. Commun., 2015, 51, 326-329.

3 Y. Hong, J. W. Y. Lam and B. Z. Tang, Chem. Soc. Rev., 2011, 40, 5361-5388.

4 J. Luo, Z. Xie, J. W. Y. Lam, L. Cheng, H. Chen, C. Qiu, H. S. Kwok, X. Zhan, Y. Liu, D. Zhu and B. Z. Tang, Chem. Commun., 2001, 1740-1741.

5 (a) Z. Chen, Z. Li, L. Yang, J. Liang, J. Yin, G.-A. Yu and S. H. Liu, Dyes Pigm., 2015, 121, 170-177; (b) J. Wei, B. Liang, X. Cheng, Z. Zhang, H. Zhang and Y. Wang, RSC Adv., 2015, 5, 71903-71910; (c) Z. Chen, Z. Li, F. Hu, G.-A. Yu, J. Yin and S. H. Liu, Dyes Pigm., 2016, 125, 169-178. 6 J. Mei, N. L. C. Leung, R. T. K. Kwok, J. W. Y. Lam and B. Z. Tang, Chem. Rev., 2015, 115, 11718-11940.

7 (a) P. Xue, J. Ding, P. Wang and R. Lu, J. Mater. Chem. C, 2016, 4, 6688-6706; (b) Z. Chen, L. Yang, Y. Hu, D. Wu, J. Yin, G.-A. Yu and S. H. Liu, RSC Adv., 2015, 5, 9375793764; (c) Z. Chen, J. Liang, Y. Nie, X. Xu, G.-A. Yu, J. Yin and S. H. Liu, Dalton Trans., 2015, 44, 17473-17477; (d) Z. Chi, X. Zhang, B. Xu, X. Zhou, C. Ma, Y. Zhang, S. Liu and J. Xu, Chem. Soc. Rev., 2012, 41, 3878-3896.

8 (a) G. Zhang, J. Lu, M. Sabat and C. L. Fraser, J. Am. Chem. Soc., 2010, 132, 2160-2162; (b) L. Bu, M. Sun, D. Zhang, W. Liu, Y. Wang, M. Zheng, S. Xue and W. Yang, J. Mater. Chem. C, 2013, 1, 2028-2035; (c) Y. Lin, G. Chen, L. Zhao, W. Z. Yuan, Y. Zhang and B. Z. Tang, J. Mater. Chem. C, 2015, 3, 112-120; (d) Z. Chen, G. Liu, R. Wang and S. Pu, $R S C A d v$. 2017, 7, 15112-15115; (e) H. Wu, C. Hang, X. Li, L. Yin, M. Zhu, J. Zhang, Y. Zhou, H. Ågren, Q. Zhang and L. Zhu, Chem. Commun., 2017, 53, 2661-2664; (f) K. C. Naeem, A. Subhakumari, S. Varughese and V. C. Nair, J. Mater. Chem. C, 2015, 3, 10225-10231; (g) D. Tu, P. Leong, Z. Li, R. Hu, C. Shi, K. Y. Zhang, H. Yan and Q. Zhao, Chem. Commun., 2016, 52, 12494-12497; (h) S. Ito, T. Taguchi, T. Yamada, T. Ubukata, Y. Yamaguchi and M. Asami, RSC Adv., 2017, 7, 16953-16962.

9 C. W. T. Leung, Y. Hong, S. Chen, E. Zhao, J. W. Y. Lam and B. Z. Tang, J. Am. Chem. Soc., 2013, 135, 62-65.

10 Z. Chen, X. Han, J. Zhang, D. Wu, G.-A. Yu, J. Yin and S. H. Liu, RSC Adv., 2015, 5, 15341-15349.

11 J. Mei, Y. Hong, J. W. Y. Lam, A. Qin, Y. Tang and B. Z. Tang, Adv. Mater., 2014, 26, 5429-5479. 